\title{
A GESTÃo dA INOVAÇÃO E O DESENVOLVIMENTO DE PRODUTOS EM EMPRESAS DE ARTEFATOS DE ALUMÍNIO NO SUDOESTE DO PARANÁ: AÇÕES PARA A SUSTENTABILIDADE
}

\section{THE INNOVATION MANAGEMENT AND PRODUCT DEVELOPMENT IN ALUMINUM ARTIFACTS COMPANIES OF PARANÁ STATE: ACTIONS FOR THE SUSTAINABILITY}

\author{
Ana Paula Debastiani Vasco ${ }^{1}$; Gilson Adamczuk Oliveira ${ }^{2}$; Gilson Ditzel Santos ${ }^{3}$; Jaiarys Capa \\ Bataglin $^{4}$; Aulison André Kummer ${ }^{5}$ \\ ${ }^{1}$ Universidade Tecnológica Federal do Paraná - UTFPR - Câmpus Pato Branco \\ ana.dvasco@yahoo.com.br \\ ${ }^{2}$ Universidade Tecnológica Federal do Paraná - UTFPR - Câmpus Pato Branco \\ gilson@utfpr.edu.br \\ ${ }^{3}$ Universidade Tecnológica Federal do Paraná - UTFPR - Câmpus Pato Branco \\ ditzel@utfpr.edu.br \\ ${ }^{4}$ Universidade de São Paulo - USP \\ jaiarys@me.com \\ ${ }^{5}$ Universidade Tecnológica Federal do Paraná - UTFPR Câmpus Pato Branco \\ aulisonkummer@hotmail.com
}

\begin{abstract}
Resumo Este artigo apresenta a primeira etapa de uma pesquisa realizada no setor de alumínio do Sudoeste do Paraná. O objetivo centra-se em uma análise focada no Processo de Desenvolvimento de Produtos (PDP), com o intuito de identificar ações para a gestão da inovação e a sustentabilidade econômica, social e ambiental. Nesta etapa se propôs conhecer o setor para dar subsidio as etapas posteriores da pesquisa. Este trabalho tem a intenção de mostrar e discutir os resultados desta etapa. Para tanto, foram realidas entrevistas semiestruturadas com gestores de três empresas de artefatos de alumínio da região Sudoeste do Paraná. Esta é uma pesquisa com abordagem qualitativa, pois, bucou conhecer ações de inovação e sustentabilidade a partir da compreensão dos sujeitos entrevistados. Observou-se que as empresas não têm um processo sistematizado no desenvolvimento de produtos e nas práticas de gestão da inovação, e que as ações para a sustentabilidade centram-se nas dimensões econômicas e ambientais previstas na legislação.
\end{abstract}

Palavras-chave: inovação; processo de desenvolvimento de produtos; sustentabilidade.

\section{Introdução}

A inovação está presente no discurso empresarial como um elemento importante para o progresso econômico de um país. Ela é entendida como o fator que mantém a competitividade no contexto capitalista, dessa forma, a constante transformação, através da inovação, é que mantém as forças internas deste sistema para o progresso (SHUMPETER, 1997). 
O capitalismo, que é impulsionado pelas inovações, também é o modelo de desenvolvimento - emergido da modernidade - que trouxe evidentes danos para o meio ambiente, a desigualdade social e o desequilíbrio econômico. E nesse contexto de tensão entre o modelo do progresso e os desequilíbrios que ele também gera é que surge o debate do desenvolvimento sustentável como uma possibilidade de superação de tais desafios. E dentro desse debate a inovação, que pode ser um fator prejudicial aos aspectos ambientais, econômicos e sociais, é uma possibilidade de reverter tal situação (BARBIERI et al, 2010).

É neste contexto de preocupação que o presente trabalho se insere. Este trabalho dedica-se a uma análise focada dentro das organizações do meio produtivo, mais especificamente no Processo de Desenvolvimento de Produtos (PDP). Compreende-se que a promoção da sustentabilidade, considerando suas diferentes dimensões, pode estar contida nas ações das empresas para o desenvolvimento dos seus produtos (TINGSTROM; KARLSSON, 2006). Portanto, este trabalho apresenta a primeira etapa de uma pesquisa realizada no setor de alumínio do Sudoeste do Paraná. Esta etapa se propôs conhecer o setor, mais especificamente as empresas de artefatos de alumínio, para dar subsidio as etapas posteriores. A pesquisa tem cunho qualitativo e foi feita a partir de entrevistas semiestruturadas. A análise dos dados foi realizada a partir das categorias definidas $a$ priori - inovação, PDP e sustentabilidade - através da técnica de análise de conteúdo, categorizando as informações em uma planilha para tornar mais acessível à análise das respostas e suas interpretações.

Este trabalho está organizado para apresentar a abordagem teórica, a metodologia utilizada neste estudo, os resultados obtidos e por fim, as considerações finais.

\section{Fundamentação teórica}

\subsection{Inovação}

A diversidade de campos em que atemática da inovação tem sido estudada é bastante abrangente. Sendo este umtema emergente no contexto empresarial, também encontra vasto espaço na literatura acadêmica. Conforme Bigliardi et al (2011) há uma linguagem que define esta temática que é mais comum, entendida como o sucesso na introdução de algo novo eútil no mercado, podendo ser novos métodos, técnicas ou práticas, produtosnovos ou significativamente alteradose serviços.

Schumpeter (1997) foi o primeiro a definir a inovação. Para ele o sistema capitalista está em constante transformação, e o que o mantém é as inovações. Compreendia o autor que as inovações não surgiam por uma demanda espontânea dos consumidores modificando o sistema produtivo através de sua pressão. Ao contrário, o empreendedor introduz uma mudança e os consumidores são “educados" para aderi-la. Além disso, afirma o autor que a inovação "significa produzir um custo 
menor por unidade acabando com a antiga "curva da oferta" e iniciando uma nova" (Idem, p.81). Schumpeter (1997) define inovação como a introduçãode um bem novo, de um bom método, ou do novo modo de produção, ainda, a abertura de um novo mercado, a aquisição de uma nova fonte de abastecimento de matéria-prima ou a realização de uma nova organização, podendo combinar essas novas criações.

O cenário ao qual se aplica o conceito de inovação mudou e, está em constante transformação. O Livro Verde da Comissão Europeia propõe que a inovação é o sucesso da produção, assimilação e exploração de coisas novas no campo econômico e social (Comissão Europeia, 1995). Conforme o Manual de Oslo (1997) define três categorias de inovação a partir da visão do mundo dos negócios: inovação de produto, processo ou serviço. Podendo se dividir em: incremental ou radical. Inovação incremental é aquela que incorpora melhorias significativas nos produtos já existentes. Já a inovação radical define-se como uma mudança drástica na maneira como o produto é consumido, a exemplo cita-se a evolução do Compact Disc (CD) para o MP3.

Vollenbroek (2002) afirma que a inovação é a introdução de uma invenção na sociedade que provocou um aumento da prosperidade das sociedades ocidentais durante o século 20. Conforme Morison (1984), a inovação pode ser considerada uma combinação dos conceitos existentes que, quando juntos, tornam possível uma atividade particular pela primeira vez. Rogers (1995) entende que a inovação refere-se à percepção dos indivíduos em relação às novidades, portanto, afirma que a inovação consiste em uma ideia prática que é percebida como nova por indivíduos. Barbieri (2007) afirma que a organização inovadora é aquela que introduz novidades, a partir de bases sistemáticas, e alcança os resultados esperados. Compreendendo bases sistemáticas como autonomia, intencionalidade e proatividade.

A partir dos anos 70 a ideia da gestão sistemática da inovação nas empresas começa a crescer gerando um amplo debate na literatura acadêmica. Dessa forma, a gestão da tecnologia e, mais recentemente, a gestão da inovaçãose tornaram importantes temas da literatura acadêmica, as quais derivam, principalmente, dos centros de difusão das grandes universidades dos EUA e Europa (CLARK e WHEELWRIGHT, 1993).

É também na década de 70, que surgem discussões sobre os limites do conceito de crescimento econômico, entendido até então como sinônimo de desenvolvimento, tratando da emergência dos problemas causados pela modernidade. Dentre eles os problemas ambientais, que lentamente começaram a serem levantados pelos diversos agentes, indivíduos, governos, organizações, entidades da sociedade civil, entre outros. Tais agentes questionam as propostas de desenvolvimento tradicional, gerador de desequilíbrios regionais e sociais, resultado dos processos de crescimento das sociedades. Podem-se identificar as seguintes etapas na evolução desta inquietação: a primeira refere-se à percepção dos problemas ambientais atribuídos a ignorância, 
negligência, dolo ou indiferença, por parte dos agentes produtores e consumidores, as quais foram combatidas com ações de natureza reativa, corretiva e repressiva; a segunda etapa é entendida como um processo de degradação ambiental generalizado, porém, restrito aos limites territoriais; portanto, acrescentam-se novos instrumentos de intervenção governamental para combater e prevenir a poluição e para melhorar os sistemas produtivos; a terceira etapa é percebida como um problema globalque pode atingir todos e que é consequência do desenvolvimento praticado em todos os países. Esta nova fase exige um questionamento quanto às políticas e metas adotadas pelos países para o seu respectivo desenvolvimento. As questões ecológicas e a própria escassez de recursos não podem ser determinadas exclusivamente por condições naturais, sendo também condicionadas pelas formas vigentes de apropriação social e exploração econômica da natureza (BARBIERI, 2005; LEFF, 2005).

Nesse contexto de preocupação, em que, sob a ótica do mercado pensava-se a inovação como uma forma de reinventar processos e produtos nas organizações como forte intuito da lucratividade (BARBIERI, 2010); e, por outra vertente, vêem-se diversos agentes, indivíduos, governos, organizações, entidades da sociedade civil, entre outros questionarem as propostas de desenvolvimento tradicional, gerador de desequilíbrios regionais e sociais, resultadodo modelo de desenvolvimento impulsionado pelo capitalismo. Neste contexto de tensão é que a inovação pode ser uma proposta de reverter tais desequilíbrios.

\subsection{Inovação e sustentabilidade}

Em 1983 a Assembleia Geral da ONU criou a Comissão de Brundtland com o objetivo de discutir as questões pertinentes aos processos de desenvolvimento adotados pelos países. Foi então, em 1987, definido o conceito a respeito deste novo modelo: “desenvolvimento sustentável é aquele que atende às necessidades do presente sem comprometer a possibilidade das gerações futuras de atenderem suas próprias necessidades" (CMMAD, 1991, p. 46). A Comissão de Brundtland encerrou seus trabalhos com o relatório denominado Nosso Futuro Comum, o qual aborda os princípios do desenvolvimento sustentável, em suas multidimensões. É neste sentido que Sachs (1993) define três dimensões prioritárias para o desenvolvimento sustentável: social, econômica e ambiental.

- A Sustentabilidade Social baseia-se nas condições do que é uma boa sociedade. Portanto, visa promover a equidade, reduzindo os diferentes padrões de vida entre as populações, dando condições melhores de vida a todos;

- A Sustentabilidade econômica refere-se à alocação e gestão mais eficientesdos recursos públicos e privados. Para alcançá-la é necessário superar as condições de dívida e do fluxo líquido de recursos financeiros das diferentes regiões, as adversidades nas relações de troca, as barreiras 
existentes nos países industrializados e, por fim, superar os entraves do acesso à ciência e à tecnologia;

- A Sustentabilidade ecológica: apóia-se na redução do consumo de recursos naturais e produção de resíduos, promovendo mais pesquisas e tecnologias limpas.

$\mathrm{Na}$ década de 80 essa questão começa a ser incorporada pelo sistema econômico. Comprando a ideia de desenvolvimento sustentável, as corporações começam a se movimentar para, segundo elas, "recuperar o tempo perdido" (LEIS, 1996). A crise ambiental veio questionar os paradigmas vigentes que impulsionavam o crescimento econômico e negavam a natureza. A sucessão da apropriação dessa crescente preocupação tornou os vários setores, nos anos 90, inseridos quase que totalmente na questão ambiental. Essa discussão alcançou a sociedade civil, Estado e o mercado (LEFF, 2001; BARBIERI, 2010). No entanto, Leis (1996) faz referência a não estagnação da questão ambiental sob o viés econômico/empresarial já que, o desenvolvimento sustentável não se refere a uma proposta linear, cartesianamente pensada,ao contrário, enfatiza a importância dessa temática permear discussões nos múltiplos setores da sociedade e a articulação dos diferentes saberes.

Neste estudo a sustentabilidade é avaliadasobre suas diferentes dimensões. Sob o prisma empresarial pode-se reduzi-la somente como um sinônimo de sobrevivência, sustentar-se economicamente para manter-se competitiva no mercado. No entanto, o intuito é pensá-la como uma proposta de debate e possível superação dos desafios ambientais, sociais e econômicos, gerados a partir do modelo de desenvolvimento ao qual se elege. Conforme Damasceno et al (2011) a sustentabilidade não é compreendida somente como uma sensibilização às questões ambientais, mas uma perspectiva que incorpore as demandas sociais e economicas também.

A esse respeito Barbieri (2010) faz referência à inovação como sendo o fator que continuamente transforma os ambientes físicos, biológicos e sociais. Dessa forma, se ela é o fator que contribuiu e contribui para o estado de degradação que se percebe, pensar sobre a possibilidade de reversão ou superação da atual situação, é pensá-latambém sobre o prisma da inovação.

Conforme Savitz e Weber (2006) a sustentabilidade é a habilidade de fazer negócios em um mundo interdependente e uma empresa sustentável é aquela capaz de gerar lucros, protegendo o meio ambiente e melhorando a vida das pessoas com quem interage. Elkington (2000) também define a sustentabilidade como uma forma de assegurar que as ações de hoje não limitarãoas opções econômicas, sociais e ambientais para as futuras gerações.

Conforme Hart e Milstein (2003), a sustentabilidade em uma organização não pode ser analisada a partir de pequenas ações, no entanto, devem ser considerados quatro aspectos essenciais: a redução do consumo de material e do nível de poluição associado à industrialização; 
transparência e capacidade de resposta em relação à sociedade civil; desenvolvimento de novas tecnologias que podem reduzir os danos ao planeta e; enfim, sugere o autor, as organizações podem conduzir suas ações para a base da pirâmide, permitindo a criação de maior riqueza e distribuição.

A Comissão Europeia (CE, 2008) definiu a eco-inovaçãocomo, novosprodutos, processos, serviços ou métodos de gestão e negócios que busca - em todo o seu ciclo de vida - prevenir ou reduzir o risco ambiental, poluição e outros impactos negativos do uso de recursos (incluindo energia). Carrillo-Hermosilla et al (2010) define a inovação sustentável como aquela que pode melhorar o desempenho, entendendo desempenho sobre os aspectos ecológicos, econômicos e sociais.

Este trabalho dedica-se a uma análise focada dentro das organizações do meio produtivo, mais especificamente no Processo de Desenvolvimento de Produtos (PDP). Sendo assim, abordamse alguns aspectos que justificam a razão do desenvolvimento sustentável ser um paradigma que deve estar inserido nas diferentes etapas do PDP, atendendo as demandas sociais, econômicas e ambientais emergentes.

\subsection{Abordagem do PDP a partir da proposta do desenvolvimento sustentável}

Para alinhamento deste trabalho no que diz respeito ao PDP foi optado pelo modelo referencial de Rozenfeld et al (2006) (Figura 1). Este divide o PDP em três macrofases: (1) prédesenvolvimento: refere-se à gestão de portfólio em que as são tratadas as estratégias empresariais e de produto. Nesta etapa define-se escopo do projeto de desenvolvimento, avaliação econômica do projeto, avaliações de capacidade de risco do projeto, definição de indicadores para monitoramento do projeto e definição de planos de negócio. (2) Desenvolvimento: esta fase caracteriza-se pela transformação dos requisitos em características de produtos, em que, prepara-se sua produção e é realizado o lançamento. As sub-etapas que compõem o desenvolvimento (foco da pesquisa) são as seguintes: Projeto Informacional - levantamento de informações junto aos clientes sobre o projeto em questão; Projeto Conceitual - com base nas informações obtidas na fase anterior, é proposto o conceito a ser adotado pelo produto; Projeto Detalhado, fase final de projeto, definido os componentes do produto, então, realiza-se o lançamento oficial do produto. (3) Pósdesenvolvimento: é a fase em que o produto já está em fase de uso no mercado. Alguns aspectos desta etapa são: definição de equipes e recursos para as alterações e correções de potenciais falhas e/ou adição de melhorias requisitadas pelos clientes; planejamento de retirada do produto do mercado; possíveis providências de descarte do material. 
Figura 1 - Modelo unificado do processo de desenvolvimento de produto

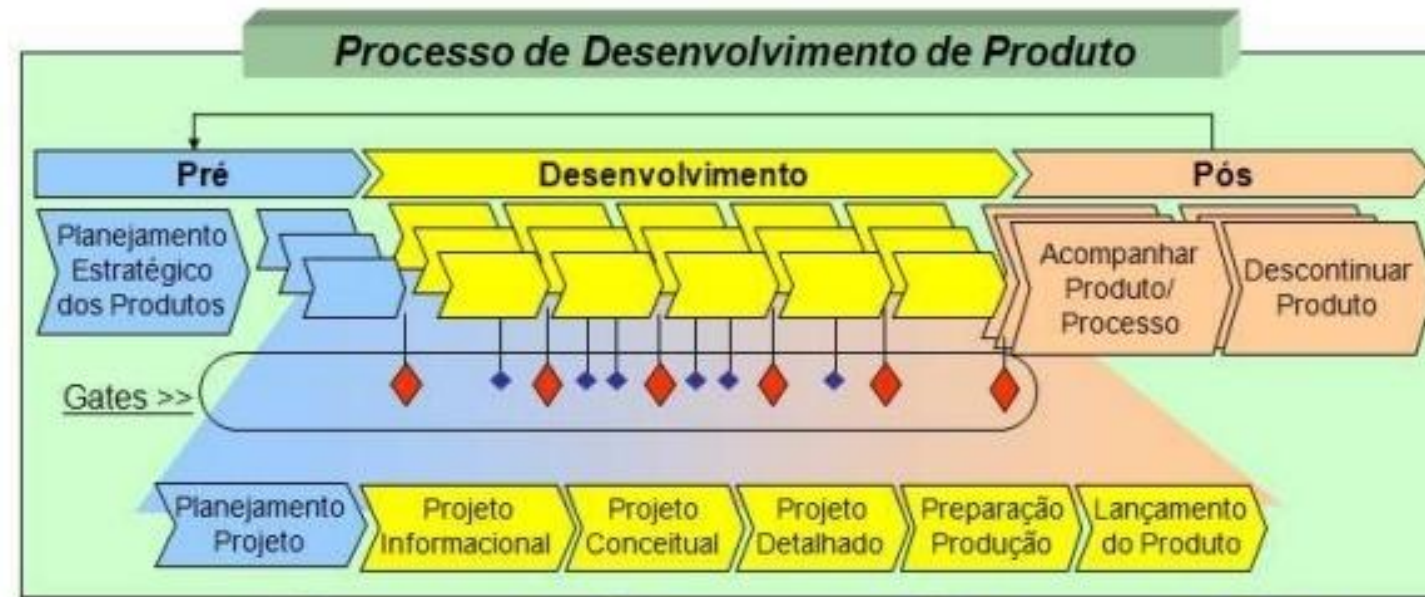

\begin{tabular}{|c|c|}
\hline $\begin{array}{c}\text { Processos } \\
\text { de apoio }\end{array}$ & Gerenciamento de mudanças de engenharia \\
& Melhoria do processo de desenvolvimento de produtos \\
\hline
\end{tabular}

Fonte: Rozenfeld et al (2006)

As diferentes abordagens do PDP, na sua maioria não integram preocupações com as questões ambientais e sociais, detendo-se, geralmente, somente sob ao viés econômico (SHARMA, 2012). Dos diferentes autores que abordam a temática, entre eles, Rozenburge e Eekels (1995), Ulrich e Eppinger (2000), Crawford e Benedetto (2000), Rozenfeld et al (2006), o referente tema é tratado de forma mais tradicional.

Existem discussões que abordam o PDP integrando as questões ambientais, tal como, Brezet e Van Hemel (1997), a do Desenvolvimento de Produtos Ambientalmente Sustentáveis - DPAS (MAXWELL e VORST, 2003) e Abele et al (2005), a Metodologia Para Desenvolvimento de Produto (MSPD - Method for Sustainable Product Development) que se estende sobre todo o ciclo de vida do produto sugerida por Byggeth et al (2007). No entanto, como este trabalho é um recorte de uma pesquisa que tem o objetivo de desenvolver uma metodologia de desenvolvimento de produto sustentável em suas três dimensões, analisar-se-á aspectos que apontem inclinações, por parte das empresas pesquisadas, para as dimensões estabelecidas por um modelo de desenvolvimento sustentável.

Optou-se pelo desenvolvimento sustentável como norteador para o PDP, pois, a partir de Magnago et al (2012) compreende-se que a sustentabilidade atende, de forma mais ampla, as questões emergentes na sociedade e também tem aplicabilidade nas macrofases do PDP. Magnago et al (2012) verificaram quinze diferentes abordagens que versam pelo menos um aspecto das categorias da sustentabilidade e as analisou a partir dos seguintes critérios: natureza da abordagem, nível organizacional, aplicação nas macrofases do PDP e impacto da abordagem nas dimensões da sustentabilidade. O que pode ser observado é o alto nível da proposta do desenvolvimento sustentável em todos os critérios ora estabelecidos o que pode indicar esta proposta como viável na 
abordagem do PDP e também para atender as demandas sociais, econômicas e ambientais emergentes.

Conforme Tingstrom e Karlsson (2006) há duas principais formas de incorporar a sustentabilidade no desenvolvimento de produto: 1) substituir os produtos existentes no portfólio da empresa por produtos com menor impacto ambiental ou; 2) incorporar na política de desenvolvimento de produto da empresa a preocupação com as questões ambientais como uma metodologia obrigatória, traduzindo em um portfólio de produtos sustentáveis. Essas duas abordagens diferentes níveis de engajamento da empresa com os problemas ambientais emergentes, sendo que a segunda forma apresentada implica em uma maior responsabilidade da empresa para com os problemas ambientais.

Nessa perspectiva Alakeson e Sherwin (2004) também distinguem quatro diferentes estágios da integração do desenvolvimento sustentável com a inovação: 1) O que o autor chama de abordagem única, em que a empresa não tem uma forma sistemática de abordar as diferentes dimensões, mas, incorpora questões específicas de sustentabilidade; 2) A abordagem ad hoc, em que as empresas consideram a importâncias das dimensões do desenvolvimento sustentável, contudo, não possuem a sistematização do processo de gestão da sustentabilidade; 3) Ferramentas de sustentabilidade, em que a empresa desenvolve ferramentas para a relação harmônica entre as questões sociais, econômicas e ambientais; 4) A integração estratégica, sendo este o estágio em que a o próprio desenvolvimento sustentável é aquele que fornece a estrutura para a inovação.

Winsemius e Guntram (1992) também fazem uma classificação dos diferentes estágios do envolvimento das empresas com as questões ambientais. Estas categorias têm sido utilizadas para classificação em diferentes trabalhos acadêmicos (TIEN et al, 2005; PEIRÓ-SIGNES et al, 2012; PETALA et al, 2010). Os autores classificam os estágios como: 1) Empresas com "respostas reativas", referindo-se àquelas que cumprem rigorosamente as leis e regulamentos, por uma pressão de políticas fiscalizatórias; 2) "Respostas receptivas", em que as empresas acreditam que devem fazer o trabalho. 3) "respostas construtivas", este se refere às empresas que vão além de seus negócios para atender as questões ambientais e buscam engajar fornecedores, clientes e até mesmo concorrentes para lidar com problemas que possam surgir no ciclo de vida de produtos. 4) "respostas proativas", refere-se às empresas dispostas a prever as mudanças ambientais - que tendem a tornar-se mais alarmante - que possam resultar em demandas dos clientes e preparar as medidas preventivas correspondentes.

\section{Metodologia da pesquisa}

Este trabalho, conforme já mencionado, tem o objetivo de conhecer o contexto das empresas de artefatos de alumínio da Mesorregião Sudoeste do Paraná para posteriormente sugerir questões 
relevantes à próxima etapa desta pesquisa que, consiste em uma fase quantitativa para em seguida propor uma metodologia de desenvolvimento de produtos para esse setor, numa abordagem sustentável. A escolha por esta região justifica-se por concentrar grande número de empresas de artefatos de alumínio e sua consequente importância regional.

Este artigo aborda a primeira etapa em que foram realizadas entrevistas com base no roteiro de questões, sendo que as respostas foram gravadas com os entrevistados cientes, os quais permitiram a gravação e o uso dos depoimentos, com o compromisso de manter o anonimato. A amostra selecionada foi não probabilística e por conveniência, a escolha das empresas consiste por estarem localizadas em diferentes cidades da Mesorregião Sudoeste do Paraná e de diferentes tamanhos a partir do critério de faturamento. Dessa forma classifica-se:

Quadro 1 - Informações da pesquisa

\begin{tabular}{|c|c|c|c|c|}
\hline & $\begin{array}{c}\text { Classificação por } \\
\text { faturamento }\end{array}$ & $\begin{array}{c}\text { Classificação por } \\
\text { número de empregados }\end{array}$ & Cidade & Entrevistado \\
\hline Empresa A & Média* & Grande* & Francisco Beltrão & Gerente Geral \\
\hline Empresa B & Micro ** & Pequena*** & Pato Branco & Gerente Geral \\
\hline Empresa C & Micro ** & Micro** & Coronel Vivida & Sócio-proprietário \\
\hline
\end{tabular}

Fonte: Pesquisa realizada, 2013.

* Faturamento maior que 3,6 milhões; Mais de 500 colaboradores;

** Faturamento até 360 mil; De 20 a 99 colaboradores.

*** Menos que 19 colaboradores.

A técnica de entrevista semiestruturada gravada justifica-se, pois, conforme Gil (1993) é guiada a partir de um roteiro de questões que o investigador explora ao longo de seu desenvolvimento. Da mesma forma Triviños (1992) afirma que a entrevista semiestruturada parte de alguns questionamentos básicos, apoiados por teorias que interessam à pesquisa, e que, durante a entrevista surgem novos questionamentos e, estes são discutidos com o entrevistado. As questões do roteiro de entrevistas iniciaram abordando questões relativas à inovação, posteriormente, sobre a metodologia utilizada, formalizada ou não, de desenvolvimento de produto e se nestes dois aspectos poderiam conter preocupações, porparte da empresa, quanto às dimensões da sustentabilidade.

Esta pesquisa tem cunho qualitativo justificando-se por seruma forma de entender um fenômeno social (RICHARDSON, 2008). Há problemas que podem ser investigados a partir de uma abordagem quantitativa, porém, este trabalho buscou identificar, a partir das entrevistas com os dirigentes das empresas selecionadas, comportamentos, atitudes, visões, valores que estão implicados nas condutas e ações concretas no que se refere à dinâmica de desenvolvimento de produto e quais inclinaçõesexistem para as dimensões do desenvolvimento sustentável.

Para análise, as categorias definidas a priori foram inovação e Projeto de Desenvolvimento de Produto (PDP), numa perspectiva sustentável, conforme mostra a Figura 2 abaixo: 


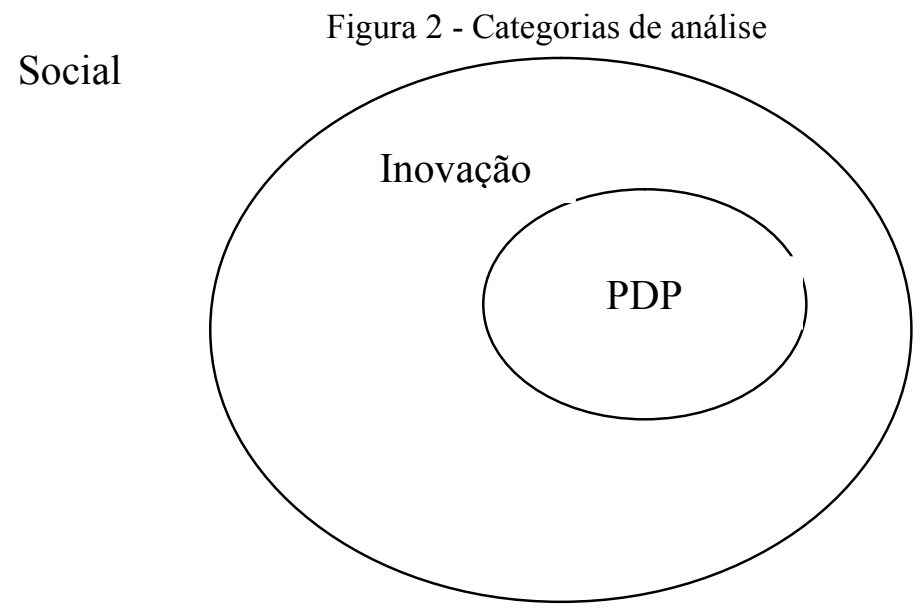

Econômico

Ambiental

Fonte: Autoria própria

A técnica de análise de conteúdo foi utilizada para análise das entrevistas realizadas. A opção se justifica por ser uma forma de análise da comunicação, através de um procedimento sistemático de descrição dos conteúdos das entrevistas, dando subsidio aos pesquisadores fazer inferências às condições pesquisadas (BARDIN, 1977).

Para tanto, foi utilizada a técnica de análise categorial temática, permitindo condensar os dados, categorizando-os em uma planilha, de forma a tornar mais acessível à análise das respostas e suas interpretações.

\subsection{Setor de alumínio no Sudoeste do Paraná: breve contexto}

O setor metal-mecânico tem grande relevância para a economia do Estado Paraná. Conforme dados há 6.676 indústrias da área metal mecânica, que geram 103.704 postos de trabalho no Estado. A base da economia paranaense se caracteriza pelo setor agrícola, mas o setor metal-mecânico vem ganhando força, conforme dados o setor cresceu $79 \%$ nos últimos dez anos (IPARDES, 2010).

Na Mesorregião Sudoeste do Paraná há 362 empresas deste setor. Este número representa: 238 de serralharias; oito fundições de metais; 31 fábricas no segmento de alumínio; 57 tornearias e fábricas de máquinas; cinco indústrias de fogões; quatro empresas de aramados; 19 fábricas de pias; móveis tubulares, tanques e recipientes de metal. Essas empresas geram cerca de 4.500 empregos diretos e cerca de mais de 2.300 empregos indiretos (SINDIMETAL-PR/SUDOESTE, 2013). Destacam-se, especialmente, as indústrias de artefatos de alumínio, especialmente, a cidade de Francisco Beltrão que é conhecida como a "capital da panela", justamente por concentrar um número considerável de indústrias do setor.

Além disso, o setor também forma um Arranjo Produtivo Local - APL que abrange as cidades de Francisco Beltrão, Marmeleiro, Pato Branco, Coronel Vivida, Bom Sucesso do Sul e 
Nova Prata do Iguaçu. Este se propôs a Criação de uma central de compras de matérias primas; Trabalho de reivindicação junto a COPEL - Companhia Paranaense de Energia Elétrica - para adequação energética; propor a viabilidade da área específica para depósito e reciclagem de resíduos sólidos e; a criação da Agência de Exportação, Compras e Intercâmbio Internacional (CHIOCHETTA, 2007).

\section{Resultados e discussões}

Tendo em vista a grande relevância do setor de alumínio na Mesorregião Sudoeste do Paraná as empresas de artefato de alumínio que foram pesquisadas, estas se caracterizam da seguinte forma:

Quadro 2 - Perfil das empresas pesquisadas

\begin{tabular}{|c|c|c|c|c|}
\hline & $\begin{array}{c}\mathrm{N} \text { de } \\
\text { funcionários }\end{array}$ & $\begin{array}{c}\text { Qtde de itens } \\
\text { Fabricados }\end{array}$ & Tempo de atuação & Produção \\
\hline Empresa A & Mais de 500 & 9 & 16 & Repuxo \\
\hline Empresa B & 41 & 600 & 15 anos & Repuxo \\
\hline Empresa C & 11 & 50 & 13 anos & Fundição \\
\hline
\end{tabular}

Fonte: Pesquisa realizada, 2013

Com relação à inovação observou-se que as empresas não têm um processo sistematizado de gestão da inovação, podendo ser reflexo da recente entrada dessa temática no mercado, especialmente em empresas afastadas dos grandes centros. Houve uma diferença de compreensão sobre a importância da inovação no contexto organizacional.

Quadro 3 - Compreensão sobre inovação

\begin{tabular}{|c|c|c|}
\hline Empresa & Fala & Tipo de inovação \\
\hline Empresa A & $\begin{array}{l}\text { A gente entende por inovação como o caminho do } \\
\text { sucesso na verdade. Praticamente o que tem de } \\
\text { tecnologia hoje a gente ta implantando pro próximo ano } \\
\text { (...) A inovação é uma busca contínua, incansável aqui da } \\
\text { empresa. É o caminho do sucesso né? (...) na empresa a } \\
\text { gente ta evoluindo, principalmente com esse segmento } \\
\text { do mercado, porque, sem inovação acho que está fora. }\end{array}$ & Produto e Processo \\
\hline Empresa B & $\begin{array}{l}\text { Devido às exigências do INMETRO... se aperfeiçoar pra } \\
\text { se manter no mercado. De uma ano pra cá a gente ta } \\
\text { trabalhando muito com desenho, formato de peças, } \\
\text { coisas desse tipo, tipo de cabo, tipo de tonel, tipo de } \\
\text { alumínio, que alumínio vamos usar. Não era muito feito } \\
\text { isso há tempos atrás, porque não tinha uma cobrança né? } \\
\text { Então, depois que começou essa cobrança do INMETRO } \\
\text { e aí certificação e tal.(..) Então, inovação eu acho que é } \\
\text { uma consequencia, porque se você vai ter que ter } \\
\text { qualidade, se o teu produto hoje não tá bom você vai ter } \\
\text { que inovar. }\end{array}$ & $\begin{array}{c}\text { Produto e } \\
\text { Organizacional }\end{array}$ \\
\hline Empresa C & $\begin{array}{l}\text { Olha, na verdade, o nosso produto, como é um produto } \\
\text { fundido. É um produto mais difícil de você trabalhar, } \\
\text { então, ele não tem muito de inovação. Na verdade ele } \\
\text { vem de tradicional mesmo né? É difícil você conseguir } \\
\text { trabalhar um produto novo... você consegue assim, } \\
\text { melhorando, mas pra você trabalhar um produto novo... } \\
\text { Começando já pelo custo dele, o fundido é, a matriz do }\end{array}$ & Produto \\
\hline
\end{tabular}




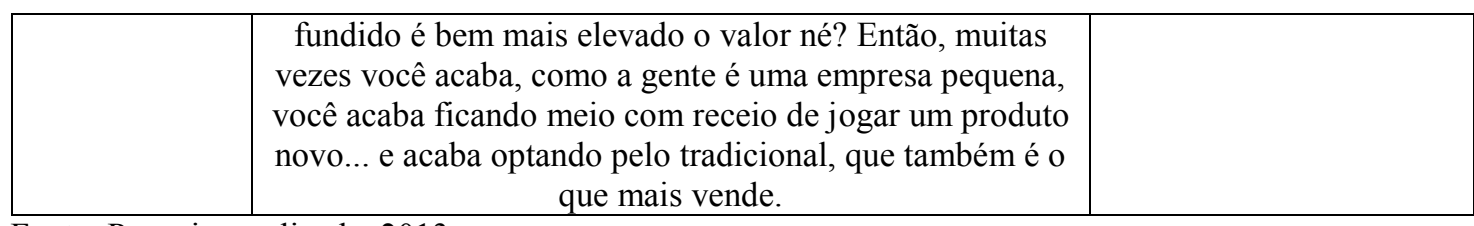

Fonte: Pesquisa realizada, 2013

A partir da análise do Quadro 3 percebe-se diferentes entendimentos sobre a questão da inovação. A empresa A reconhece a importância no contexto organizacional, inclusive remete-se a ela como um dos fatores de sobrevivência no mercado. Afirmação que faz referência à ideia de Schumpeter, já explanada acima quando afirma que o sistema capitalista está em constante transformação, e a inovação é a forma que mantém como sistema hegemônico. Este é um contraponto à empresa $\mathrm{C}$ que mostrou ser a inovação um aspecto não crucial à sua empresa. Essas diferentes interpretações podem remeter-se a aspectos interessantes. Observa-se que a primeira caracteriza-se como média empresa, com alto faturamento, vasta estrutura física e de pessoal, diferentemente da empresa C (Quadro 3 acima) que, além de ser proporcionamente menor em diversos aspectos, tem também uma gestão familiar. A afirmação desta pode ser reflexo das configurações existentes nas pequenas empresas, geralmente, conduzidas pela intuição, por métodos menos formalizados. Tal como afirma Oliveira e Simonetti (2010) ao mostrarem que a percepçãoentendida como o conhecimento aprendido a partir do contexto interno, tendo em vista que a interpretação e a intuição são formadas a partir da experiência e do conhecimento adquirido podem conduzir as decisões, bem como os negócios de uma micro empresa.

Diferentemente a empresa B relaciona a inovação com as questões de normas legalmente estabelecidas, o que pode melhorar a qualidade do produto, por isso, sua interpretação sobre a inovação centra-se na melhoria no produto (inovação de produto) e a certificação (inovação organizacional). O INMETRO no último ano instituiu uma certificação compulsória para o setor de panelas metálicas exigindo alguns critérios que farão as empresas se adequarem às diretrizes de qualidade ou extinguindo muitas delas do mercado, tal como afirmaram os entrevistados.

Quando questionados sobre os produtos considerados inovadores da empresa, os três entrevistados afirmaram terem lançado um produto inovador. O Quadro 4 mostra as características destes produtos.

\begin{tabular}{|c|c|c|c|c|}
\hline & $\begin{array}{c}\text { Produto destacado } \\
\text { como inovador }\end{array}$ & $\begin{array}{c}\text { Tipo de } \\
\text { Inovação }\end{array}$ & $\begin{array}{c}\text { Levantamento da } \\
\text { demanda }\end{array}$ & Fala \\
\hline Empresa A & $\begin{array}{c}\text { Todos os anos são } \\
\text { lançados }\end{array}$ & Incremental & $\begin{array}{c}\text { Funcionários } \\
\text { Clientes }\end{array}$ & $\begin{array}{c}\text { "Todo ano (é lançado). Não tem } \\
\text { como não lançar." }\end{array}$ \\
\hline Empresa B & Pudinzeira & Incremental & $\begin{array}{c}\text { Funcionários } \\
\text { Clientes } \\
\text { Concorrência }\end{array}$ & $\begin{array}{c}\text { "...teria uma pudinzeira que foi } \\
\text { criada um tempo atrás que deu } \\
\text { uma praticidade maior pra } \\
\text { pessoa que gosta de fazer } \\
\text { pudim, e se destacou no }\end{array}$ \\
\hline
\end{tabular}




\begin{tabular}{|c|c|c|c|c|}
\hline & & & $\begin{array}{c}\text { mercado, ela é em banho maria, } \\
\text { não precisa colocar dentro de } \\
\text { uma panela com água" }\end{array}$ \\
\hline Empresa C & Panela 9X40 & Incremental & $\begin{array}{c}\text { Funcionários } \\
\text { Clientes } \\
\text { Concorrência } \\
\text { tem nove centímetros de altura, } \\
\text { só 9X40 de diâmetro. Então, ela } \\
\text { é bem baixinha. Surgiu porque } \\
\text { um cliente veio e pediu" }\end{array}$ \\
\hline
\end{tabular}

Fonte: Pesquisa realizada, 2013

Observa-se que o tipo de inovação predominantemente é incremental e estas partem dos funcionários, colaboradores e da concorrência, no caso da empresa B e C. Buscou-se entender, a partir da grande área da inovação como as empresas desenvolvem seus produtos e quais as implicações das dimensões da sustentabilidade nesse processo.

A partir das entrevistas realizadas notou-se que nenhuma das três empresas tem um processo sistematizado de desenvolvimento de produto. Nas três empresas pesquisadas, com exceção da empresa C que não foi identificada nenhuma ação no pré-desenvolvimento, a forma de desenvolvimento de produto segue as seguintes etapas: levantamento de demanda - podendo ser internamente, através dos funcionários ou externamente a partir da concorrência ou dos clientes; tentativa do desenvolvimento do produto; colocação no mercado e; alterações e correções de potenciais falhas e/ou adição de melhorias requisitadas pelos clientes. 
Quadro 5 - Etapas do PDP

\begin{tabular}{|c|c|c|c|c|c|}
\hline & \multicolumn{4}{|c|}{ PDP (Rozenfeld et al, 2006) } & \multirow{2}{*}{$\begin{array}{c}\text { Aspectos } \\
\text { sociais, } \\
\text { econômicos } \\
\text { e ambientais } \\
\text { observados }\end{array}$} \\
\hline & $\begin{array}{c}\text { Pré- } \\
\text { desenvolvimento }\end{array}$ & Desenvolvimento & Evidências & $\begin{array}{c}\text { Pós- } \\
\text { desenvolvimento }\end{array}$ & \\
\hline \multirow[t]{2}{*}{$\begin{array}{c}\text { Empresa } \\
\mathrm{A}\end{array}$} & \multirow[t]{2}{*}{$\begin{array}{l}\text { Realiza reuniões } \\
\text { com a direção } \\
\text { para avaliar } \\
\text { informalmente a } \\
\text { viabilidade } \\
\text { econômica e } \\
\text { tecnológica do } \\
\text { produto. }\end{array}$} & $\begin{array}{c}\text { Projeto } \\
\text { Informacional }\end{array}$ & $\begin{array}{l}\text { A empresa levanta } \\
\text { informação a partir: 1) } \\
\text { demanda de mercado } \\
\text { (de forma informal) } \\
\text { através da solicitação } \\
\text { do cliente por } \\
\text { produtos novos e; } 2 \text { ) a } \\
\text { direção da empresa. }\end{array}$ & \multirow[t]{2}{*}{$\begin{array}{l}\text { São realizadas } \\
\text { readequações } \\
\text { nos produtos } \\
\text { conforme } \\
\text { indicação do } \\
\text { mercado. }\end{array}$} & \multirow{2}{*}{$\begin{array}{c}\text { A empresa } \\
\text { reutiliza } \\
100 \% \text { da } \\
\text { sobra de } \\
\text { material e } \\
\text { Tratamento } \\
\text { de resíduos } \\
\text { atmosféricos } \\
\text { conforme } \\
\text { legislação; }\end{array}$} \\
\hline & & $\begin{array}{c}\text { Projeto } \\
\text { Detalhado }\end{array}$ & $\begin{array}{l}\text { Lançamento do } \\
\text { produto }\end{array}$ & & \\
\hline \multirow[b]{2}{*}{$\begin{array}{c}\text { Empresa } \\
\text { B }\end{array}$} & \multirow[b]{2}{*}{$\begin{array}{c}\text { Realiza reuniões } \\
\text { com a direção } \\
\text { para avaliar } \\
\text { informalmente a } \\
\text { viabilidade } \\
\text { econômica e } \\
\text { tecnológica do } \\
\text { produto. }\end{array}$} & $\begin{array}{c}\text { Projeto } \\
\text { Informacional; }\end{array}$ & $\begin{array}{c}\text { A empresa levanta } \\
\text { informações a partir } \\
\text { dos colaboradores e } \\
\text { clientes. }\end{array}$ & \multirow[b]{2}{*}{$\begin{array}{l}\text { São realizadas } \\
\text { readequações } \\
\text { nos produtos } \\
\text { conforme } \\
\text { indicação do } \\
\text { mercado. }\end{array}$} & \multirow{2}{*}{$\begin{array}{c}\text { A empresa } \\
\text { reaproveita } \\
\text { a sobra de } \\
\text { material } \\
\text { (vende } \\
\text { fábrica de } \\
\text { discos de } \\
\text { alumínio) e } \\
\text { faz o } \\
\text { tratamento } \\
\text { de resíduos } \\
\text { atmosféricos } \\
\text { conforme } \\
\text { legislação }\end{array}$} \\
\hline & & $\begin{array}{c}\text { Projeto } \\
\text { Detalhado }\end{array}$ & $\begin{array}{l}\text { Lançamento do } \\
\text { produto }\end{array}$ & & \\
\hline \multirow[b]{2}{*}{$\begin{array}{c}\text { Empresa } \\
\mathrm{C}\end{array}$} & \multirow[b]{2}{*}{ Não realiza } & $\begin{array}{c}\text { Projeto } \\
\text { Informacional; }\end{array}$ & $\begin{array}{c}\text { A empresa levanta } \\
\text { informações a partir } \\
\text { dos colaboradores e } \\
\text { clientes. }\end{array}$ & \multirow{2}{*}{$\begin{array}{l}\text { São realizadas } \\
\text { readequações } \\
\text { nos produtos } \\
\text { conforme } \\
\text { indicação do } \\
\text { mercado }\end{array}$} & \multirow{2}{*}{$\begin{array}{c}\text { A empresa } \\
\text { reaproveita } \\
\text { a sobra de } \\
\text { material } \\
\text { (vende) e } \\
\text { faz o } \\
\text { tratamento } \\
\text { de resíduos } \\
\text { atmosféricos } \\
\text { conforme } \\
\text { legislação }\end{array}$} \\
\hline & & $\begin{array}{c}\text { Projeto } \\
\text { Detalhado }\end{array}$ & $\begin{array}{l}\text { Lançamento do } \\
\text { produto }\end{array}$ & & \\
\hline
\end{tabular}

Fonte: Pesquisa realizada, 2013

Observa-se no quadro acima as etapas do PDP realizadas pelas empresas pesquisadas. Não são formalmente organizadas, mas, pode-se observar a partir da pesquisa realizada que há tais ações no desenvolvimento de novos produtos. A partir do que ela realiza dentro de algumas das etapas sugeridas por Rozenfeld et al (2006) foram identificadas as seguintes ações ou percepções (por parte do empresário) dentro da perspectiva das categorias do desenvolvimento sustentável: reutilização do alumínio utilizado e tratamento dos resíduos atmosféricos.

A partir das categorizações propostas por Tingstrom e Karlsson (2006), Alakeson e Sherwin (2004) e Winsemius e Guntram (1992) as empresas pesquisadas encontram nos estágios, conforme Quadro 6. 
Quadro 6 - Categorização PDP, inovação e estratégias ambientais

\begin{tabular}{|c|c|c|c|c|c|c|}
\hline & \multicolumn{2}{|c|}{ Tingstrom e Karlsson (2006) } & \multicolumn{2}{|c|}{ Alakeson e Sherwin (2004) } & \multicolumn{2}{|c|}{$\begin{array}{l}\text { Winsemius e Guntram } \\
\text { (1992) }\end{array}$} \\
\hline & $\mathrm{DS}(*)$ e PDP & Evidências & $\begin{array}{l}\mathrm{DS}(*) \text { e } \\
\text { Inovação }\end{array}$ & Evidências & $\begin{array}{l}\text { Estratégias } \\
\text { ambientais }\end{array}$ & Evidências \\
\hline $\begin{array}{c}\text { Empres } \\
\text { a A }\end{array}$ & $\begin{array}{c}\text { A empresa } \\
\text { incorpora a } \\
\text { dimensão } \\
\text { econômica no } \\
\text { PDP. }\end{array}$ & $\begin{array}{c}\text { Não } \\
\text { identificou } \\
\text { ações em prol } \\
\text { das questões } \\
\text { ambientais e } \\
\text { sociais no } \\
\text { desenvolvime } \\
\text { nto de } \\
\text { produtos. }\end{array}$ & $\begin{array}{c}(1) \\
\text { Abordage } \\
\mathrm{m} \text { do tema } \\
\text { único. }\end{array}$ & $\begin{array}{l}\text { Observou-se } \\
\text { que as } \\
\text { inovações } \\
\text { realizadas pela } \\
\text { empresa teve } \\
\text { uma } \\
\text { centralidade no } \\
\text { aspecto } \\
\text { econômico, } \\
\text { não havendo } \\
\text { preocupações } \\
\text { ambientais ou } \\
\text { sociais. }\end{array}$ & $\begin{array}{l}\text { (2) Resposta } \\
\text { receptiva }\end{array}$ & $\begin{array}{l}\text { A empresa } \\
\text { além de } \\
\text { cumprir a } \\
\text { legislação, } \\
\text { mostrou } \\
\text { conheciment } \\
\text { o quanto aos } \\
\text { danos } \\
\text { ambientais } \\
\text { do seu } \\
\text { produto. }\end{array}$ \\
\hline $\begin{array}{c}\text { Empres } \\
\text { a B }\end{array}$ & $\begin{array}{c}\text { A empresa } \\
\text { incorpora a } \\
\text { dimensão } \\
\text { econômica no } \\
\text { PDP. }\end{array}$ & $\begin{array}{c}\text { Não } \\
\text { identificou } \\
\text { ações em prol } \\
\text { das questões } \\
\text { ambientais e } \\
\text { sociais no } \\
\text { desenvolvime } \\
\text { nto de } \\
\text { produtos. }\end{array}$ & $\begin{array}{c}(1) \\
\text { Abordage } \\
\mathrm{m} \text { do tema } \\
\text { único. }\end{array}$ & $\begin{array}{l}\text { Observou-se } \\
\text { que as } \\
\text { inovações } \\
\text { realizadas pela } \\
\text { empresa teve } \\
\text { uma } \\
\text { centralidade no } \\
\text { aspecto } \\
\text { econômico, } \\
\text { não havendo } \\
\text { preocupações } \\
\text { ambientais ou } \\
\text { sociais. }\end{array}$ & $\begin{array}{c}\text { (1) Resposta } \\
\text { Reativa }\end{array}$ & $\begin{array}{c}\text { A empresa } \\
\text { mostrou } \\
\text { concentrar } \\
\text { seu esforço } \\
\text { no } \\
\text { compriment } \\
\text { o da } \\
\text { legislação. }\end{array}$ \\
\hline $\begin{array}{c}\text { Empres } \\
\text { a C }\end{array}$ & $\begin{array}{c}\text { A empresa } \\
\text { incorpora a } \\
\text { dimensão } \\
\text { econômica no } \\
\text { PDP. }\end{array}$ & $\begin{array}{c}\text { Não } \\
\text { identificou } \\
\text { ações em prol } \\
\text { das questões } \\
\text { ambientais e } \\
\text { sociais no } \\
\text { desenvolvime } \\
\text { nto de } \\
\text { produtos. }\end{array}$ & $\begin{array}{c}\text { (1) } \\
\text { Abordage } \\
\mathrm{m} \text { do tema } \\
\text { único. }\end{array}$ & $\begin{array}{l}\text { Observou-se } \\
\text { que as } \\
\text { inovações } \\
\text { realizadas pela } \\
\text { empresa teve } \\
\text { uma } \\
\text { centralidade no } \\
\text { aspecto } \\
\text { econômico, } \\
\text { não havendo } \\
\text { preocupações } \\
\text { ambientais ou } \\
\text { sociais. }\end{array}$ & $\begin{array}{c}\text { (1) Resposta } \\
\text { Reativa }\end{array}$ & $\begin{array}{c}\text { A empresa } \\
\text { mostrou } \\
\text { concentrar } \\
\text { seu esforço } \\
\text { no } \\
\text { compriment } \\
\text { o da } \\
\text { legislação. }\end{array}$ \\
\hline
\end{tabular}

Fonte: Pesquisa realizada, 2013

* Desenvolvimento Sustentável (DS)

O que se pode observar a partir do exposto é que as empresas pesquisadas encontram-se em estágios iniciais no que tange a gestão inovação e ao PDP em suas relações com a sustentabilidade. Pôde-se chegar a algumas evidências que sustentam essa afirmação. Na classificação de Tingstrom e Karlsson (2006) o quepôde ser observado é que, a partir daquilo que as empresas realizam das etapas do PDP, há uma concentração na dimensão econômica, não tendo ações evidentes no que tange aos aspectos sociais e ambientais. No que se refere à classificação de Alakeson e Sherwin (2004), as inovações também se concentram sobre a sustentabilidade econômica, essa é uma evidência presente nos produtos que a empresas possuem e também naquilo que elas consideram como sendo uma inovação realizada por elas (Quadro 4). A abordagem de Winsemius e Guntram 
(1992), referente às estratégias ambientais, mostrou que as três empresas pesquisadas não têm ações além da legislação do setor. Destaca-se a empresa A por mostrar uma sensibilidade e conhecimento acerca dos problemas ambientais que o alumínio pode causar e fazer referência ao cumprimento da legislação para diminuir tais danos. Diferentemente das empresas B e C que afirmaram cumprir a legislação, no entanto, desconhecem os danos ambientais que a matéria-prima utilizada pode causar.

\section{Considerações finais}

Este trabalho se propôsconhecer o setor de alumínio do Sudoeste do Paraná a partir de três casos para dar subsidio à pesquisa que se segue, conforme já mencionado. A partir do exposto são feitas algumas considerações.

Os processos de gestão da inovação e do PDP não são sistematizados, portanto, a gestão destes é de forma mais intuitiva. Observou-se que as ações das empresas com relação à proposta do desenvolvimento sustentável concentraram-se no aspecto econômico e nas exigências legais com relação ao meio ambiente. O primeiro justifica-se por ser parte intrínseca da natureza das empresas. O segundo aspecto fica evidente por duas questões: Ficou clara a importância das políticas de proteção ambiental para a efetividade das ações para sustentabilidade ambiental. As ações relatadas pelas empresas, tal como, destino da sobra de alumínio, gases poluentes, são previamente medidas tomadas a partir das exigências legais (MINTER, 1979). Outro aspecto relevante é que a dimensão ambiental está fortemente presente no discurso do desenvolvimento sustentável, especialmente no setor empresarial. Resultado também da incorporação desse discurso pelos diversos setores da sociedade, sendo que, o setor econômico é o mais recente neste debate, conforme já relatado neste trabalho (LEIS, 2006). No entanto, quando se pensa no desenvolvimento numa perspectiva sustentável, este deve estar integrado com suas diferentes dimensões. A dimensão econômica está intrinsecamente em todo o processo empresarial e é, de forma geral, a dimensão prioritária nas ações empresariais. As questões sociais devem também ser incorporadas nas preocupações da empresa a partir da promoção de ações para equidade e qualidade de vida. Tal como afirma Leff (2001) o esforço dessa mudança não deve concentrar-se em estabelecer um conceito capaz de "ecologizara economia" ou "capitalizar a natureza" apenas, caso contrário, seriam medidas paliativas, numa relação causa e efeito, duramente criticada pela proposta inicial do desenvolvimento sustentável. Raynaut (2004) ao abordar tal assunto sugere a seguinte questão: sustentabilidade para quem?

Por fim, é evidente que a inovação, muito presente no discurso empresarial, contribuiu e contribui para a degradação que se depara atualmente, mas, entende-se que está nela a possibilidade de reverter tal situação (BARBIERI, 2010). Por isso, a importância de se pensar em um Projeto de Desenvolvimento de Produto, que pode ser uma inovação, numa perspectiva sustentável que 
abarque as dimensões consideradas por esta proposta: econômico, social e ambiental.

\begin{abstract}
This paper presents the first step of a survey conducted in the aluminum sector, in Southwest of Paraná. The purpose is an analysis focused on Product Development Process (PDP), in order to identify actions for the management of innovation and the economic, social and environmental sustainability. This step had the purpose to know the industry to give subsidy to the later stages of the research. This study has a qualitative approach, in which were conducted with semi-structured interviews with three companies of artifacts aluminum area. The investigated companies do not have a systematic process in product development and practice of innovation management. Furthermore, the sustainability actions focus on the economic and environmental dimensions contained in the legislation.
\end{abstract}

Keywords: innovation; process of product development; sustainability.

\title{
Referências
}

ABELE, E.; ANDERL, R.; BIRKHOFER, H, G. Environmentally-friendly product development: methods and tools. Londres: Springer, p. 0-318, 2005. crossref

ALAKESON V., SHERWIN, C. Innovation for sustainable development. Forum of the Future, 2004.

BARBIERI, J. C. Desenvolvimento e Meio Ambiente: as estratégias de mudanças da agenda 21. Rio de Janeiro: Editora Vozes Ltda., 2005. Organizações inovadoras sustentáveis. In: BARBIERI, J. C; SIMANTOB, M. Organizações inovadoras sustentáveis: uma reflexão sobre o futuro das organizações. São Paulo, Atlas, 2007.

BARBIERI, J. C. et al. Inovação e Sustentabilidade: Novos Modelos e Proposições. RAE, São Paulo, v.50, n. 2. p. 146 - 154, Abr/Jun 2010.

BARDIN, L. Análise de conteúdo. Lisboa: Edições 70, 1977.

BYGGETH, S.; BROMAN, G.; ROBÈRT, K. A Method for sustainable product development based on a modular system of guiding questions. Journal of Cleaner Production, v. 15, p. 1-11, 2007. cross ref

BIGLIARDI, B., COLACINO, P., et al (2011) Innovative characteristics of small and medium enterprises. Journal of Technology Management \& Innovation, v. 6, n. 2, p.83-93. 2011. crossref

BREZET, H.; VAN HEMEL, C. Ecodesign: a promising approach to sustainable production and consumption. Paris: UNEP, 1997.

CARRILLO-HERMOSILLA, J., DEL RÍO, P., KONNOLA, T. Diversity of eco-innovations: reflections fromselected case studies. Journal of Cleaner Production, 18, 1073 e 1083, 2010.

CE (European Commission). Call for Proposals under the Eco-innovation 2008 Programme. DG Environment. 2008. Disponível em: <http://ec.europa.eu/environment/etap/ecoinnovation/library_en.htm>. Acesso em: 15 jan. 2013.

CLARK, K. B., WHEELWRIGHT, S. Managing new product and process development: text and case. New York, USA: The Free Press, 1993.

CRAWFORD, C.M., BENEDETTO, C.A.D. New product management, EUA: MqcGraw-Hill, International Edition, 2000.

COMISSÃO MUNDIAL SOBRE MEIO AMBIENTE E DESENVOLVIMENTO (CMMAD). Nosso futuro comum. Rio de Janeiro: Fundação Getúlio Vargas, 1991.

ELKINGTON, J. Cannibals with forks: the triple bottom line of 21st century business. New Society Publishers, Gabriola Island, British Columbia, 1998. 
GIL, A. C. Métodos e Técnicas da Pesquisa Social. Ed 5. São Paulo: Atlas, 1993.

HART, S. L. MILSTEIN, M. B. Creating Sustainable Value. Academy of Management Executive, v. 17, n.2, 56-67, 2003. cross ref

IPARDES. Cadernos Estatísticos. Cadernos Municipais IPARDES. Curitiba: IPARDES, 2010.

LEIS, H.. 1996. O Labirinto: Ensaios sobre Ambientalismo e Globalização. Blumenau, Editora Gaia/FURB.

MAGNAGO, P. F. Sustentabilidade em Desenvolvimento de Produtos: uma proposta para a classificação de abordagens. Revista Científica Eletrônica de Engenharia da Produção, v.12, n. 2, p. 351-376, abr./jun, 2012.

MAXWELL, D.; VORST, R. Developing sustainable products and services. Journal of Cleaner Production, v. 11, p. 883-895, 2003. cross ref

MINTER. Disponível em: <http://www.ima.al.gov.br/legislacao/portarias-ministeriais/Portaria\%20nb0\%2053.79.pdf>. Acesso em: 15 jan. 2013.

MORISON, E. Gunfire at sea: Conflict over a new technology. In R. Westrum K. S. (Eds.), Complex organizations: Growth, struggle, and change. Englewood Cliffs, NJ: Prentice-Hall, p. 131-143, 1984.

OLIVEIRA, S. R. M.; SIMONETTI, V. M. M. Intuição e percepção no processo decisório de microempresa. Revista da Micro e Pequena Empresa (FACCAMP), v. 3, p. 52 - 66, 2010.

PEIRÓ-SIGNES, Á. et al. Environmental's Proactivity Measurement Tool Validation. International Business \& Economics Research Journal - Special Edition .v. 11, n 13, p. 1433-1438, 2012.

PETALA, E., et al. The role of new product development briefs in implementing sustainability: a case study. Journal of Engineering and Technology Management, v. 27, p. 172-182, 2010. cross ref

RAYNAUT, C. Revista Desenvolvimento e Meio Ambiente. In: Meio Ambiente e Desenvolvimento: um novo campo do saber a partir da perspectiva interdsciplinar. Curitiba: Editora UFPR. № 10, p. 21-32, 2004.

RICHARDSON, R. J. Pesquisa Social: método e técnicas. 3 ed. São Paulo: Atlas, 2008.

ROGERS, E.M. Diffusion of innovations. 4th ed. New York: The Free Press, 1995.

ROZENBURG N.F.M; EEKELS J. Product design: fundamentals and methods, Chichester: John Wiley and Sons, 1995.

ROZENFELD, H. et al. Gestão do desenvolvimento de produtos: uma referência para a melhoria do processo. Saraiva, São Paulo, 2006.

SACHS, I. Estratégias de transição para o século XXI: desenvolvimento e meio ambiente. São Paulo: Nobel, 1993.

SAVITZ, A.W., WEBER, K. The triple bottom line: how today's best-run companies are achieving economic, social and environmental success and how you can too. John Willey \& Sons, San Francisco, 2006.

SHARMA, 2012. Resource-constrained product development: Implications for green marketing and green supply chains. Industrial Marketing Management, v. 41, n. 4, p.599-608. May 2012. crossref

SCHUMPETER, J. A instabilidade da Economia. In: CARNEIRO R. (org). Os Clássicos da Economia, Vol. 2. São Paulo: Ática, 1997.

SCHUMPETER, J. Teoria do Desenvolvimento Economico: uma investigação sobre lucros, capital, crédito, juro e ciclo economico. São Paulo: Nova Cultura, 1997.

SINDMETAL. Disponível em: <http://www.sindimetalsudoeste.com.br/>. Acesso em: 02 fev. 2013. 
TIEN, S., CHUNG, Y., TSAI, C. An empirical study on the correlation between environmental design implementation and business competitive advantages in Taiwan's industries. Technovation, v. 25, p. 784-794, 2005. cross ref

TINGSTROM J., KARLSSON R. The relationship between environmental analyses and the dialogue process in product development. Journal of Cleaner Production, v. 14, p. 1409-1419, 2006. crossref

TRIVIÑOS, A. N. S. Introdução à Pesquisa em Ciências Sociais: a pesquisa qualitativa em educação. São Paulo: Atlas, 1987.

ULRICH, K. T.; EPPINGER, S. D. Product design and development. United States of America: Irwin McGraw -Hill Companies, ed. 2, 2000.

VOLLEMBROEK, F. A. Sustainable Development and challenge of innovation. Journal Clear Production, v. 10, p. 215-223, 2002. cross ref

WINSEMIUS, P., GUNTRAM, U. Responding to environmental business challenger. Business Horizons, v. 35, n. 2 p. 12-20, 1992. crossref

\section{Dados dos autores}

Nome completo: Ana Paula Debastiani Vasco

Filiação institucional: Universidade Tecnológica Federal do Paraná - UTFPR Câmpus Pato Branco Departamento: Administração

Função ou cargo ocupado: Professora

Endereço: Via do Conhecimento, Km 01

Telefone para contato: 4632202511

e-mail: ana.dvasco@yahoo.com.br

Nome completo: Gilson Adamczuk Oliveira

Filiação institucional: Universidade Tecnológica Federal do Paraná - UTFPR Câmpus Pato Branco

Departamento: Engenharia da Produção

Função ou cargo ocupado: Professor

Endereço: Via do Conhecimento, Km 0

Telefone para contato: 4632202511

e-mail: gilson@utfpr.edu.br

Nome completo: Gilson Ditzel Santos

Filiação institucional: Universidade Tecnológica Federal do Paraná - UTFPR Câmpus Pato Branco

Departamento: Administração

Função ou cargo ocupado: Professor

Endereço: Via do Conhecimento, Km 01

Telefone para contato: 4632202511

e-mail:ditzel@utfpr.edu.br

Nome completo: Jaiarys Capa Bataglin 
Filiação institucional: Universidade de São Paulo - USP

Departamento: Administração

Função ou cargo ocupado: Doutoranda

Endereço: Av. Prof. Luciano Gualberto, 908

Telefone para contato: 4699350887

e-mail: jaiarys@me.com

Nome completo: Aulison André Kummer

Filiação institucional: Universidade Tecnológica Federal do Paraná - UTFPR Câmpus Pato Branco

Departamento: Programa de Pós Graduação em Desenvolvimento Regional

Função ou cargo ocupado: Mestrando

Endereço: Via do Conhecimento, Km 01

Telefone para contato: 4632202511

e-mail: aulisonkummer@hotmail.com

Submetido em: 21/10/2013

Aceito em: 22/10/2014 